\title{
High-temperature polyimide nanofoams for microelectronic Applications
}

\author{
J.L. Hedrick ${ }^{\mathrm{a}}$, K.R. Carter ${ }^{\mathrm{a}}$, H.J. Cha ${ }^{\mathrm{a}}$, C.J. Hawker ${ }^{\mathrm{a}}$, R.A. DiPietro ${ }^{\mathrm{a}}$, J.W. Labadie ${ }^{\mathrm{a}}$, R.D. Miller ${ }^{\mathrm{a}}$, T.P. \\ Russell $^{\mathrm{a}}$, M.I. Sanchez ${ }^{\mathrm{a}}$, W. Volksen ${ }^{\mathrm{a}}$, D.Y. Yoon ${ }^{\mathrm{a}}$, David Mecerreyes ${ }^{\mathrm{b}}$, \\ R. Jérôme ${ }^{b}$, James E. McGrath ${ }^{c}$
}

a IBM Research Divisinn, Almaden Research Center: 650 Harry Road. San Jose, CA 95120.6099, USA

b Université de L'Etat a Liège. Sart Tilman, Liège, Belgium

c Virginia Polytechnic Institute and State University: 211I Hahn Hall, Blacksburg, VA 24061.0344.

USA

\begin{abstract}
Foamed polyimides have been developed in order to obtain thin film dielectric layers with very low dielectric constants for use in microelectronic devices. In these systems the pore sizes are in the nanometer range, thus, the term 'nanofoam'. The polyimide foams are prepared from block copolymers consisting of thermally stable and thermally labile blocks, the latter being the dispersed phase. Foam formation is effected by thermolysis of the thermally labile block, leaving pores of the size and shape corresponding to the initial copolymer morphology. Nanofoams prepared from a number of polyimides as matrix materials were investigated as well as from a number of thermally labile polymers. The foams were characterized by a variety of experiments including TEM, SAXS, WAXD, DMTA, density measurements. refractive index measurements and dielectric constant measurements. Thin film foams, with high thermal stability and low dielectric constants approaching 2.0 , can be prepared using the copolymer/nanofoam approach.
\end{abstract}

Keywords: Nanofoams; Foamed polyimides: Dielectric constants; Microelectronic devices; Polyimides

\section{Introduction}

Organic polymeric materials have long played significant roles in the microelectronics industry either in applications as structural components or in comparatively low-performance system elements such as cards, cables or circuit boards. However, the use of polymeric materials in the fabrication of multichip modules (MCM) or on chips has been much less pervasive, since inorganics (alumina or silicon oxides) have typically dominated these components which are crucial to system cycle time. Among the many approaches to decrease signal propagation delays in both the on-chip wiring, which constitutes the device to device interconnection and is typically designated to the 'back end of the line' (BEOL), or module wiring on MCMs, the reduction of the dielectric constant of the insulator medium is the most common approach. It is in these critical wiring components that high-performance organic polymers are finding increasing application as dielectric insulators. In principle, the employment of organic polymers in these devices allows lower cost manufacturing because the materials can be spincoated rather than vacuum processed for deposition. However, the major driving force for the implementation of polymeric insulators is their much lower dielectric constant as compared to the inorganic alternatives.

The velocity of pulse propagation in these structure is inversely proportional to the square root of the dielectric constant of the medium [1]. Hence, decreases in the dielectric constant of the insulator materials translate directly into improvements in machine cycle time. The cycle time is, of course, also directly proportional to the length of the conductor line wiring. The pitch or distance between conductor lines must, therefore, be minimized to improve cycle time. The minimum spacing between signal lines is dictated by noise issues or 'cross-talk' which result from induced current in conductors adjacent to active signal lines. The lateral extent of this field-induced noise is again dependent upon the dielectric constant of the insulator material. A reduction of the insulator dielectric constant permits the signal lines to be closer together, allowing designers to reduce the length of conductor lines and thereby improve machine cycle time accordingly [1]. 
Although polymeric insulators have several attractive properties, including ease of processing and low dielectric constant, in all other requirements they have serious shortcomings when compared to the inorganic alternative. Insulating materials for chip and module applications must be able to withstand the high temperature associated with the processes used to deposit metal lines, anneal devices and to join chips to modules [1]. Although a wide variety of polymers have been evaluated for use in microelectronics applications, polyimides have emerged as the favored class of materials [2-6]. The rigid and semi-rigid aromatic polyimides, in particular PMDA/ODA and BPDA/PDA, show an excellent combination of thermal and mechanical properties, which include low thermal expansion coefficient, high modulus and tough ductile mechanical properties as judged by high elongations to break. In addition, these properties are largely retained to $400^{\circ} \mathrm{C}$, above which a partial softening or flow is observed in some cases. These desirable properties reflect the high degree of molecular order and packing $[7,8]$. For instance, the polymer chains of PMDA/ODA polyimide assume locally extended conformations in a smectic-like layered order [7]. Furthermore, imidization of these polyimide films in contact with a substrate produces substantial anisotropic orientation of the molecules parallel to the surface [7-9]. This orientation results in physical and optical properties that are anisotropic $[10,11]$. This results in a high thermal expansion coefficient and low modulus perpendicular to the plane of the film as well as anisotropic swelling behavior. These effects are even more pronounced for the BPDA/PDA poly-imide. Another manifestation of the orientation is a corresponding anisotropy in the dielectric constant [11]. In particular, the in-plane constant can be as much as 0.7 to 0.8 higher than the out-of-plane dielectric constant. This is clearly an unacceptable limitation to device design. Furthermore, the advantages realized by polymeric materials over inorganics are largely negated.

The most common approach for modifying the dielectric properties of polyimides has been via the incorporation of fluorinated substituents such as hexafluoroisopropylidene linkages [12] and pendent trifluoromethyl groups $[13,14]$. While this approach can result in films with dielectric constants as low as 2.6 and low water absorption, the mechanical properties are often compromised. The addition of pendent trifluoromethyl groups appears to circumvent this drawback, but the incorporation of sufficient trifluoromethyl groups into the polymer is synthetically difficult. Alternatively, the dielectric constant of polyimides can be lowered through the introduction of kinks and separator linkages in the polymer backbone to reduce the chain packing [15]. When these structural modifications were copolymerized with the judicious choice of fluorine-containing comonomers, polyimides with dielectric constants in the range of 2.4-2.8 were achieved [15].

An alternative to the above procedure is to generate a polyimide foam to reduce the dielectric constant substantially while maintaining the desired thermal and mechanical properties of the aromatic polyimide. The reduction in the dielectric constant is simply achieved by replacing a significant part of the polymer with air which has a dielectric constant of 1 . However, there are restraints on these materials. It is obvious that the pore size must be much smaller than the film thickness or any microelectronic features. Secondly, it is necessary that the pore must be closed cell, i.e., the connectivity between the voids must be minimal. Thirdly, the volume fraction of the voids must be as high as possible. Any of these can alter the mechanical properties of the film and, hence, structural stability of the foam, especially at high temperatures $\left(\sim 400^{\circ} \mathrm{C}\right)$. Failure to satisfy the criteria could lead to a foam collapse or to a material with limited use for microelectronics applications.

In order to meet all requirements described above, a new means of generating a polyimide foam with pore sizes in the nanometer regime has been developed. This approach involves the use of phase separated block copolymers comprised of a high thermally stable $T_{g}$ polymer and a second component, which can undergo clean thermal decomposition with the evolution of volatile byproducts to form a closed-cell, porous structure. Certain block copolymers can be induced to undergo thermodynamically controlled phase separation to provide a matrix containing a dispersed phase which is spherical in morphology at equilibrium, monodisperse in size and discontinuous. Furthermore, the molecular structure and molecular weight of the block segments allows precise control over both the size and volume fraction of the dispersed phase. By designing the block copolymers such that the matrix material is a thermally stable polymer with a high $T_{g}$ and the dispersed phase is a labile polymer that undergoes thermolysis at a temperature below the $T_{g}$ of the matrix to give volatile reaction products, one can prepare foams with pores in the nanometer dimensional regime that are closed structures containing nanometer size dispersed pores that contain air. 


\section{Experimental}

\subsection{Materials}

N-methyl-2-pyrrolidone (NMP), N-cyclohex-yl-2-pyrrolidone (CHP), pyridine and acetic anhydride were purchased from Aldrich and used without purification. The pyromellitic dianhydride

(PMDA) (Chriskev Co.) was sublimed $3 \mathrm{x}$ prior to use. The cr-methylstyrene and styrene were dried over $\mathrm{CaH} 2$ at $25^{\circ} \mathrm{C}$ and distilled before polymerization. The 1,1-bis(4-aminophenyl)-1-phenyl-2,2,2trifluoroethane (3FDA) and diethyl py-romellitate diacyl chloride were prepared according to a literature procedure [16,17]. Hydroxyl terminated poly(styrene), poly(a-methylstyrene) and oligomers of styrene and a-methylstyrene were prepared anionically and subsequently derivatized to the aminoend group according to literature procedures [18-21]. Poly(styrene) oligomers of controlled molecular weight, distribution and amino-end functionality were also prepared via free radical methods $[22,23]$. The functional propylene oxide and methyl methacrylate oligomers were prepared according to literature procedures $[24,25]$.

\subsection{Polymerizations}

Triblock copolymers were prepared in a two-stage process, which included the poly(amic acid) formation followed by imidization. First, the amino functional propylene oxide oligomer $\left(\bar{M}_{\mathrm{n}}=5600\right.$ $\mathrm{g} / \mathrm{mol})(0.25 \mathrm{~g}, 0.045 \mathrm{mmol})$ and 3FDA $(0.486 \mathrm{~g}, 1.42 \mathrm{mmol})$ were charged into a flask together with the solvent, NMP $(10 \mathrm{ml})$. The PMDA $(0.3145 \mathrm{~g}, 1.44 \mathrm{mmol})$ was later added to the solution at $5^{\circ} \mathrm{C}$, yielding the target poly(amic acid) in $24 \mathrm{~h}$. Imidization of the poly(amic acid) was accomplished either thermally with a dehydrating cosolvent (i.e., CHP) or chemically with an acetic anhydride/pyridine mixture. For the case of chemical imidization, excess acetic anhydride $(0.2952 \mathrm{~g}, 2.89 \mathrm{mmol})$ and pyridine $(0.2287 \mathrm{~g}, 2.89 \mathrm{mmol})$ were added and the reaction mixture was slowly heated to $60^{\circ} \mathrm{C}$ and held for 6-8 $\mathrm{h}$. The resulting polymers were precipitated in methanol and heated $\left(80^{\circ} \mathrm{C}\right)$ in a vacuum oven for $24 \mathrm{~h}$. For the case of thermal imidization, CHP was used together with NMP as a cosolvent $\left(50 / 50\right.$ vol\%), since CHP is not miscible with water above $\sim 80^{\circ} \mathrm{C}$ thus effectively dehydrating the system. Imidization was accomplished by heating the reaction mixture to $180^{\circ} \mathrm{C}(24 \mathrm{~h})$ according to a procedure developed by McGrath and co-workers [26]. The resulting polymers were isolated in a water/methanol mixture, rinsed with isopropanol and dried in a vacuum oven $\left(50^{\circ} \mathrm{C}\right)$.

The amic ester propylene oxide triblock copolymers were prepared by the co-reaction of the amino terminated propylene oxide oligomers with 3FDA and PMDA diethyl ester di-acyl chloride in NMP in the presence of $N$-methylmorpholine. A detailed procedure designed to prepare an amic ester propylene oxide copolymer with a propylene oxide oligomer of $5600 \mathrm{~g} \mathrm{~mol}^{-3}$ molecular weight with 25 wt $\%$ propylene oxide composition is provided. A three-necked flask equipped with an overhead stirrer and addition funnel was charged with propylene oxide oligomer $(0.25 \mathrm{~g}, 0.045 \mathrm{mmol})$, 3FDA (0.4873 $\mathrm{g}, 1.42 \mathrm{mmol}$ ), and carefully rinsed with $20 \mathrm{ml}$ of NMP. Throughout the polymerization $\mathrm{N}_{2}$ was passed through the system. The solution was then cooled to $-5^{\circ} \mathrm{C}$ and $\mathrm{N}$-methylmorpholine $(0.322 \mathrm{~g}, 3.18$ mmol) was added to the solution. The PMDA diethyl ester diacyl chloride $(0.502 \mathrm{~g}, 1.446 \mathrm{mmol})$ was dissolved in $-25 \mathrm{ml}$ of methylene chloride, and added in increments over a $2 \mathrm{~h}$ period so as to slowly approach the stoichiometric end point. The reaction was allowed to proceed overnight and isolated by precipitation in methanol/water, rinsed with water (to remove excess salts) and subjected to an isopropanol rinse (to remove possible homopolymer contamination), and dried in a vacuum oven.

\subsection{Characterization}

NMR spectra (in DMSO-d $\mathrm{d}_{6}$ or $\mathrm{CDCl}_{3}$ ) were recorded on a IBM WP 250 spectrometer operating at $250.1 \mathrm{MHz}\left({ }^{1} \mathrm{H}\right)$ and $62.9 \mathrm{MHz}\left({ }^{13} \mathrm{C}\right)$ with chemical shifts reported in ppm relative to tetramethylsilane. Films for mechanical and thermal analysis were cast from NMP and cured at various temperatures as noted to effect solvent removal and imidization. Glass transition temperatures, taken as the midpoint of the change in slope of the baseline, were measured on a Du Pont 1090 instrument with a heating rate of $10^{\circ} \mathrm{C} / \mathrm{min}$. Thermal gravimetric analyses (TGA) of the polymer films were conducted on a Perkin-Elmer model TGA-7 with a heating rate of 10 " $\mathrm{C} / \mathrm{min}$ for the variable scans, and the isothermal scans were performed at various temperatures over a ten hour period. Dynamic mechanical measurements were made on a Polymer Laboratories Dynamic Mechanical 
Thermal Analyzer (DMTA) in the tension mode with a heating rate of $10^{\circ} \mathrm{C} / \mathrm{min}(10 \mathrm{~Hz})$. Density measurements were obtained with a gradient column composed of water and calcium nitrate. The column was calibrated against a set of beads of known densities and maintained at $25^{\circ} \mathrm{C}(\mathrm{d} .=1.00$ 1.42). At least two specimens were used for each density measurement. Measurements were made on a Metricon Prism Coupler (PC-2000), which is an optical waveguide technique providing both in-plane and out-of-plane refractive indices at $633 \mathrm{~nm}$ wavelength.

\section{Results and discussion}

The successful implementation of the block copolymer approach to polyimide nanofoams requires the judicious combination of polyimide with the thermally labile coblock. The material requirements for the polyimide block are stringent and require thermally stable, high-T, polyimides, which can be readily copolymerized with the appropriate labile block. A number of polyimides were surveyed and the structures and characteristics of these polyimides are shown in Scheme 1. Each of the polyimide homopolymers had high $\mathrm{T}_{\mathrm{s}}$ 's near $370^{\circ} \mathrm{C}$ and decomposition temperatures of $\sim 500^{\circ} \mathrm{C}$.

Among the requirements for the thermally decomposable coblock include the synthesis of welldefined functional oligomers amenable towards copolymerization with polyimide. This block must also decompose quantitatively into unreactive species that can easily diffuse through a glassy polyimide matrix. The temperature at which thermal decomposition of the labile block occurs is critical; it should be sufficiently high to permit standard film preparation and solvent removal yet be significantly below the $T_{g}$ of the polyimide block to avoid foam collapse. Thermally labile co-blocks investigated include poly(propylene oxide), poly(methy1 methacrylate), poly(styrene) and poly $(\alpha-$ methylstyrene).

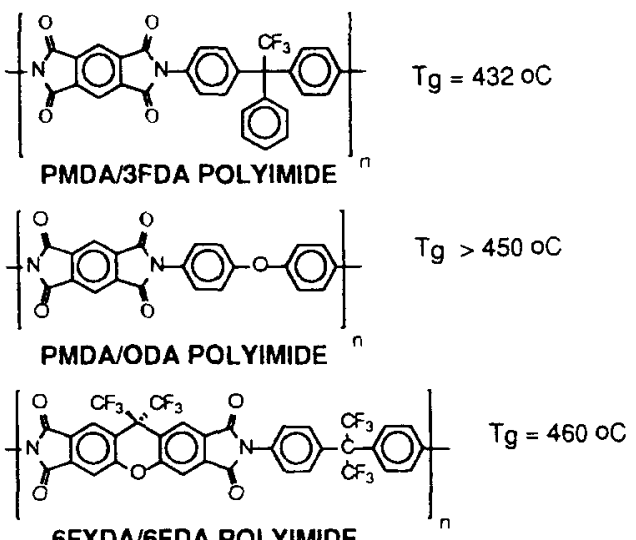

6FXDA6FDA POLYIMIDE

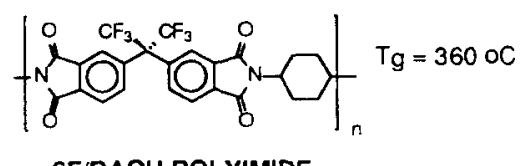

6F/DACH POLYIMIDE

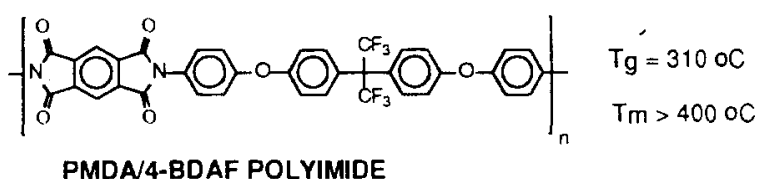

Scheme 1 .

Each decomposes quantitatively into small molecules in an appropriate temperature regime.

Poly(propylene oxide) is stable in an inert atmosphere up to $300^{\circ} \mathrm{C}$ or higher [25]. However, in the presence of oxygen, poly(propylene oxide) decomposes rapidly between 2.50 and $300^{\circ} \mathrm{C}$. Fig. 1 shows the TGA thermogram of poly(propylene oxide) which was isothermally heated at $275^{\circ} \mathrm{C}$ in air. Within $20 \mathrm{~min}$, a quantitative decomposition is observed. The thermal degradation profiles for the styrenic oligomers are shown in Fig. 2. The poly(a-methylstyrene) blocks begin to decompose at about $300^{\circ} \mathrm{C}$ while the poly(styrene) and styrenela-methylstyrene copolymers begin to degrade at slightly higher temperatures. A poly(styrene) block made by 'living' free radical polymerization (i.e., TEMPO- 
poly(styrene)) was also examined and began to degrade at temperatures somewhat lower than observed for the anionically polymerized poly(styrene) $\left(\sim 350^{\circ} \mathrm{C}\right)[23]$. All of the styrenic blocks could be obtained as monohydroxy-terminated oligomers, which permitted for their eventual incorporation into imide block copolymers as described below. The characteristics of selected labile blocks are shown in Table 1.

Table 1

Characteristic of aromatic amine functional thermally labile oligomers

\begin{tabular}{|c|c|c|c|c|}
\hline $\begin{array}{l}\text { Sample } \\
\text { entry }\end{array}$ & $\begin{array}{l}\text { Thermally labile } \\
\text { block type }\end{array}$ & $\begin{array}{l}\text { Polymer- } \\
\text { ization } \\
\text { method }\end{array}$ & $\begin{array}{l}\text { Molecular } \\
\text { weight } \\
\text { (g/mol) }\end{array}$ & $\begin{array}{l}T_{g} \\
\left({ }^{\circ} \mathrm{C}\right)\end{array}$ \\
\hline $1 a$ & $\begin{array}{l}\text { poly }(\alpha \text {-methyl- } \\
\text { styrene) }\end{array}$ & anionic & 12000 & 155 \\
\hline $1 \mathrm{~b}$ & poly(styrene) & anionic & 14000 & 100 \\
\hline 1c & $\begin{array}{l}\text { styrene/ } \\
\alpha \text {-methylstyrene } \\
\text { copolymer }\end{array}$ & $\begin{array}{l}(4 / 1) \\
\text { anionic }\end{array}$ & 14000 & 100 \\
\hline 1d & polystyrene & $\begin{array}{l}\text { free } \\
\text { radical }\end{array}$ & 13000 & 100 \\
\hline 1e & $\begin{array}{l}\text { poly(propylene } \\
\text { oxide) }\end{array}$ & anionic & 5600 & -65 \\
\hline \multirow[t]{2}{*}{ 1f } & $\begin{array}{l}\text { poly(capro- } \\
\text { lactone) }\end{array}$ & $\begin{array}{l}\text { ring } \\
\text { opening }\end{array}$ & 10000 & \\
\hline & & & & $T_{\mathrm{m}}=60$ \\
\hline
\end{tabular}

The formation of block polyimide copolymers requires the preparation of labile block oligomers that had been derivatized to contain a single aryl amine unit. Usually, this was accomplished by reacting monohydroxy terminated oligomers with either 4-nitrobenzoylchloride or 4-aminophenyl chloroformate [24]. The resulting nitro-terminated polymers were then hy-drogenated yielding monofunctional amine-terminated oligomers. These oligomers were, in turn, incorporated into imide copolymers by either of two syntectic routes. Scheme 2 shows the reaction pathway leading to polyimides via a two step poly(amic alkyl ester) route (Scheme 3). The labile block oligomer was reacted with stoichiometric amounts of the appropriate diamine and diethyl pyromellitate diacyl chloride giving the intermediate poly(amic alkyl ester) intermediate. This intermediate is useful because it can be isolated, characterized and it is soluble in a variety of organic solvents. The poly(amic alkyl ester) can then be solvent processed into thin films and heated to effect imidization to give the corresponding polyimide block copolymers. Copolymers can also be prepared via the standard two step poly(amic acid) route (Scheme 3). The labile block oligomer was reacted with stoichio- metric quantities of the appropriate diamine and dianhydride. The resulting poly(amic acid) solutions were then cast to give thin films and heated or, in the case of soluble polyimides, chemically imidized in solution and subsequently isolated by precipitation. Depending upon the particular polyimide matrix, either or both of the synthetic routes were used to obtain the desired copolymers. 


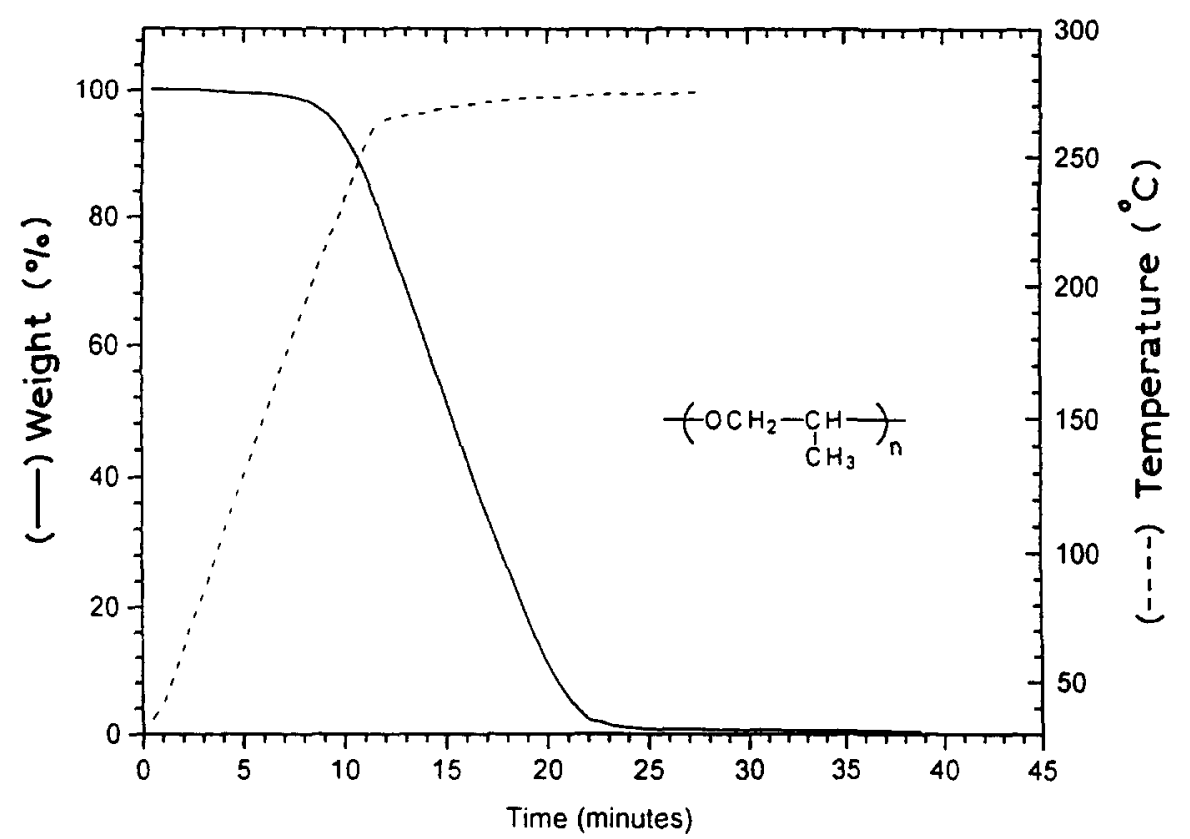

Fig. 1. Thermogravimetric analysis of poly(propylene oxide) in air.

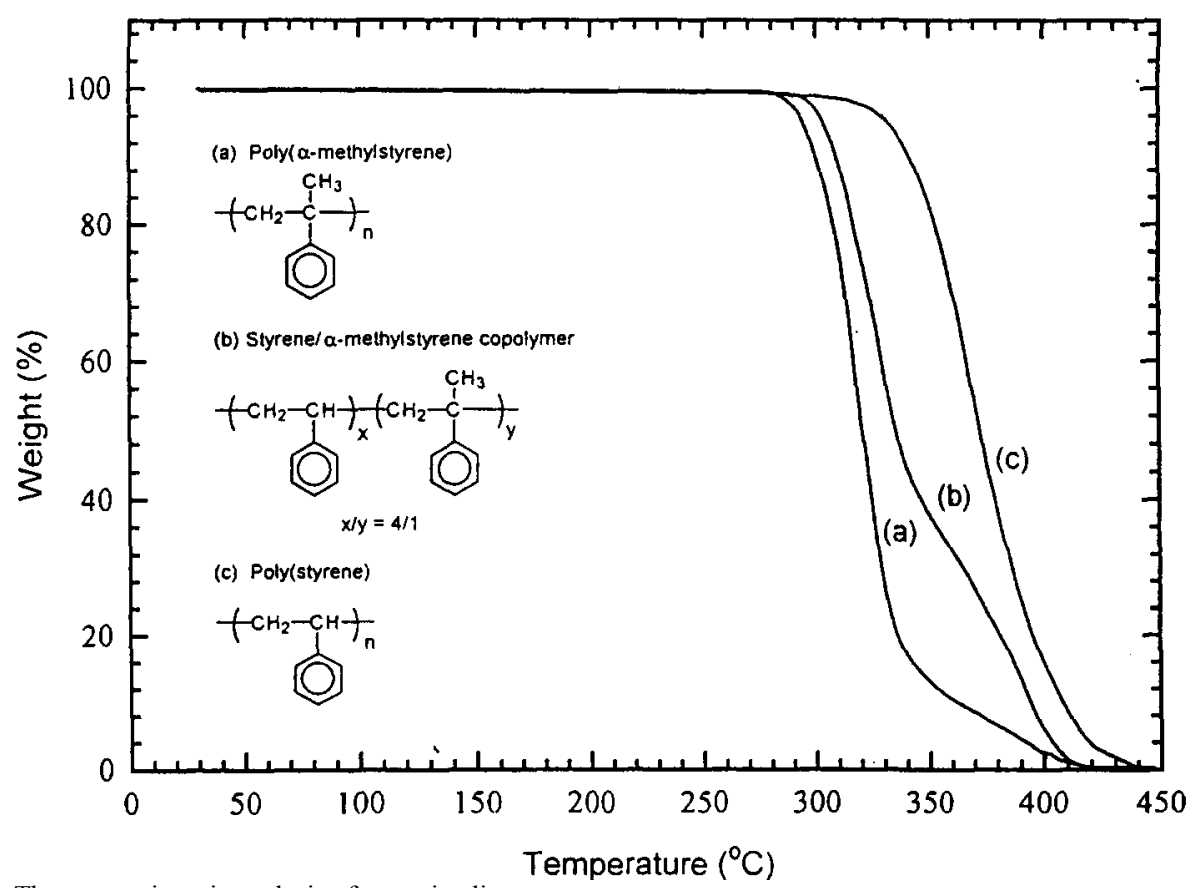

Fig. 2. Thermogravimetric analysis of styrenic oligomers. 


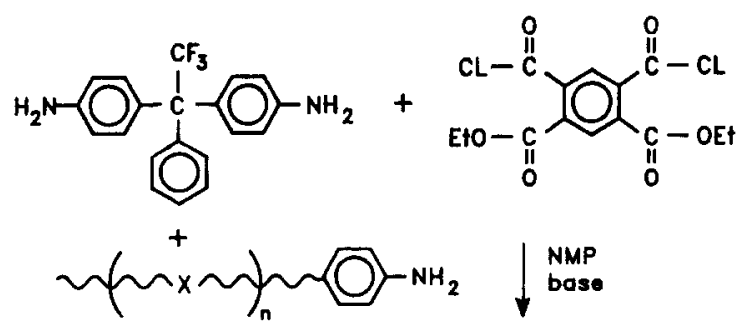

Poly(amlc othyl ester) block copolymer

Processable/soluble intermediate
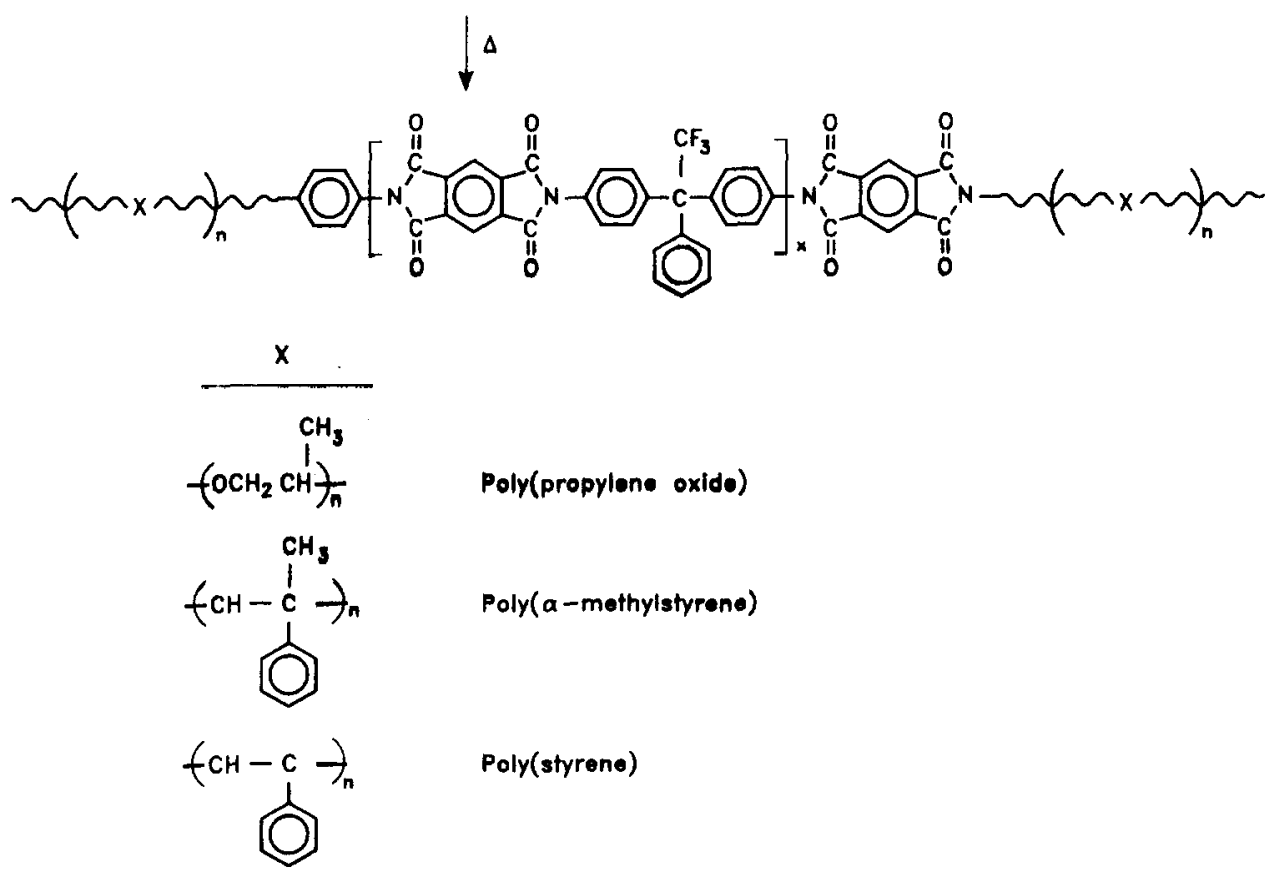

Poly(propylone oxido)<smiles>CC(=O)C(C)(C)C(C)C</smiles>

Poly(methyl methacrylate)

Scheme 2 .

$$
\left(\mathrm{CO}\left(\mathrm{CH}_{2}\right)_{5} \mathrm{O}\right) \quad \text { Poly(caprolactono) }
$$

The characteristics of selected block copolymers are shown in Table $2 .{ }^{1} \mathrm{H}-\mathrm{NMR}$ spectroscopy was used to determine the amount of the thermally labile block actually incorporated into the copolymers. These values were in good agreement with thermal gravimetric analysis performed on the samples. Block copolymers containing variable amounts of labile block were produced, although we have concentrated our efforts on copolymers containing 15-30\% labile block rationalizing that these would, most likely, afford the non-interconnected nanofoams.

The processing window for film and foam formation was established primarily with the PMDA/3FDA imide-based copolymers, since these copolymers are soluble and can be isolated and characterized at various stages of processing or imidization. It is critical that the decomposition of the labile block should occur substantially below the $T_{g}$ of the polymer matrix. 
<smiles>Nc1ccc(C(F)(c2ccc(N)cc2)C(F)(F)F)cc1</smiles>
6FDAm<smiles>CC(C)(C)OC(C)(C)OC(=O)c1ccc(N)cc1</smiles>

\section{FXDA}

$25 \mathrm{~h} \downarrow$ hMP or $70^{\circ} \mathrm{C}$

$16 \mathrm{~h}$
Labile Block

Poly(propylene oxide)

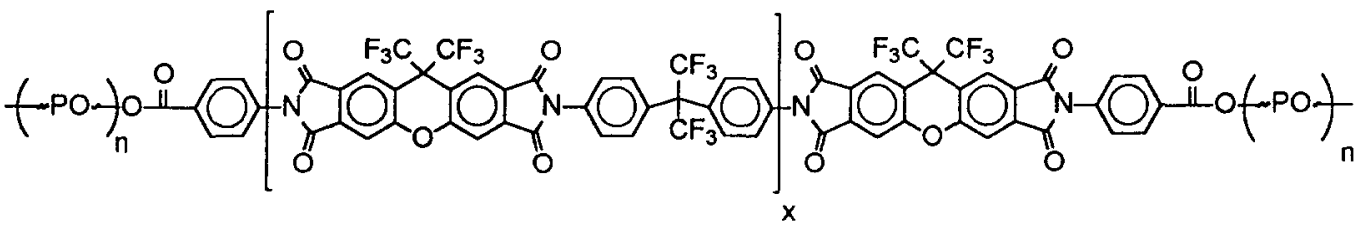

6FXDA6FDA-co-Poly(propylene oxide) Polyimide

Scheme 3 .

Table 2

Characteristics of block copolymers

\begin{tabular}{|c|c|c|c|c|c|c|}
\hline \multirow{3}{*}{$\begin{array}{l}\text { Copolymer } \\
\text { entry }\end{array}$} & \multirow{3}{*}{$\begin{array}{l}\text { Polyimide type } \\
\text { and form }\end{array}$} & \multirow{3}{*}{$\begin{array}{l}\text { Thermally labile } \\
\text { block type }\end{array}$} & \multicolumn{3}{|c|}{ Thermally labile block } & \multirow{3}{*}{$\begin{array}{l}\text { Volume fraction } \\
\text { labile block (\%) }\end{array}$} \\
\hline & & & \multirow[t]{2}{*}{ Charge } & \multicolumn{2}{|c|}{ Incorporated } & \\
\hline & & & & ${ }^{1} \mathrm{H}-\mathrm{NMR}$ & $\overline{\text { TGA }}$ & \\
\hline 2 & PMDA/3FDA (imide) & poly(propylene oxide) & 15 & 9.9 & 9 & 11 \\
\hline 3 & PMDA/3FDA (imide) & poly(propylene oxide) & 25 & 23 & 22 & 27 \\
\hline 4 & PMDA/3FDA (imide) & poly ( $\alpha$-methylstyrene) & 25 & 20 & 24 & 27 \\
\hline 5 & PMDA/3FDA (alkyl ester) & poly ( $\alpha$-methylstyrene) & 25 & - & 24 & 27 \\
\hline 6 & PMDA/3FDA (alkyl ester) & poly(styrene) & 20 & 18 & 19 & 2 \\
\hline 7 & PMDA/3FDA (alkyl ester) & $\alpha$-methylstyrene/styrene & 20 & 15 & 14 & 18 \\
\hline 8 & PMDA/ODA (alkyl ester) & poly(propylene oxide) & 25 & 22 & 23 & 28 \\
\hline 9 & PMDA/4-BDAF (alkyl ester) & poly(propylene oxide) & 24 & 18.7 & 19.3 & 25 \\
\hline 10 & 6FXDA/6FDA (imide) & poly $(\alpha$-methylstyrene) & 18 & 16.3 & 16 & 22 \\
\hline 11 & 6FXDA/6FDA (imide) & poly ( $\alpha$-methylstyrene) & 25 & 22 & 21 & 29 \\
\hline 12 & PMDA/3FDA (alkyl ester) & poly(caprolactone) & 25 & 22 & 20 & 25 \\
\hline
\end{tabular}

Furthermore, the casting solvent must be effectively removed, without labile block degradation, to minimize plasticization of the polyimide matrix, which would further narrow the processing window (i.e., temperature difference between $T_{g}$ polyimide and decomposition temperature of labile block). Samples were cast from NMP, cured, and the processing window for film and foam formation was established using ${ }^{1} \mathrm{H}-\mathrm{NMR}$, TGA and dynamic mechanical measurements. Since most of the labile blocks are stable to $300^{\circ} \mathrm{C}$ in nitrogen, coblock samples cured to this temperature to remove the casting solvent should be stable. IR, ${ }^{1} \mathrm{H}-\mathrm{NMR}$ and calorimetry measurements indicated that the imidization was essentially quantitative under these conditions, with minimal loss to the labile block composition as measured by TGA [25]. 
Table 3

Characteristics of polyimide foams

\begin{tabular}{|c|c|c|c|}
\hline $\begin{array}{l}\text { Sample } \\
\text { entry }\end{array}$ & $\begin{array}{l}\text { Initial labile } \\
\text { block com- } \\
\text { position } \\
\text { (vol\%) }\end{array}$ & $\begin{array}{l}\text { Density } \\
\left(\mathrm{g} / \mathrm{cm}^{3}\right)\end{array}$ & $\begin{array}{l}\text { Volume frac- } \\
\text { tion of voids } \\
\text { (porosity) } \\
(\%)\end{array}$ \\
\hline $\begin{array}{c}\text { PMDA/3FDA } \\
\text { polyimide }\end{array}$ & - & 1.35 & - \\
\hline 2 & 11 & 1.17 & 13 \\
\hline 3 & - & 1.11 & 18 \\
\hline 4 & 24 & 1.13 & 16 \\
\hline 5 & 24 & $\begin{array}{l}\text { intercon- } \\
\text { nected } \\
\text { pores }\end{array}$ & 30 \\
\hline 6 & 22 & 1.17 & 14 \\
\hline 7 & 18 & $\begin{array}{l}\text { intercon- } \\
\text { nected } \\
\text { pores }\end{array}$ & 19 \\
\hline $\begin{array}{l}\text { PMDA/ODA } \\
\text { polyimide }\end{array}$ & - & 1.41 & - \\
\hline 8 & 20 & 1.41 & $\begin{array}{l}\text { sample } \\
\text { collapsed }\end{array}$ \\
\hline $\begin{array}{l}\text { PMDA/4-BDAF } \\
\text { polyimide }\end{array}$ & - & 1.47 & - \\
\hline 9 & 25 & 1.12 & 24 \\
\hline $\begin{array}{c}\text { 6FXDA/6FDA } \\
\text { polyimide }\end{array}$ & - & 1.49 & - \\
\hline $10^{\circ}$ & 22 & 1.21 & 19 \\
\hline 11 & 29 & 1.17 & 22 \\
\hline 12 & 25 & 1.11 & 18 \\
\hline
\end{tabular}

The generation of the nanofoam was accomplished by subjecting the copolymer film to subsequent thermal treatment after curing and/or solvent removal to decompose the labile coblock. The temperature range and atmosphere was varied depending on the type of labile block. For instance, the propylene oxide-based copolymers were heated to $240^{\circ} \mathrm{C}$ in air for $6 \mathrm{~h}$, followed by a post-treatment at $300^{\circ} \mathrm{C}$ for $2 \mathrm{~h}$ to complete the degradation of the propylene oxide component. The degradation process was followed by thermogravimetric analysis (TGA) and ${ }^{1} \mathrm{H}-\mathrm{NMR}$. Under these conditions, quantitative degradation was observed with no evidence of residual by-products nor chemical modification to the polyimide. Conversely, the degradation of the styrenic-based copolymers was accomplished by a step-wise process so as to minimize the degradation rate of these blocks. In all cases, the labile blocks could be completely thermally degraded as evidenced by NMR, TGA and IR measurements. The densities of the foamed polymers were measured by a gradient density column. Porosity and void formation was also studied by small angle X-ray scattering, and calibrated IR absorption [27]. Pertinent characteristics of a number of polyimide foams are shown in Table 3. 


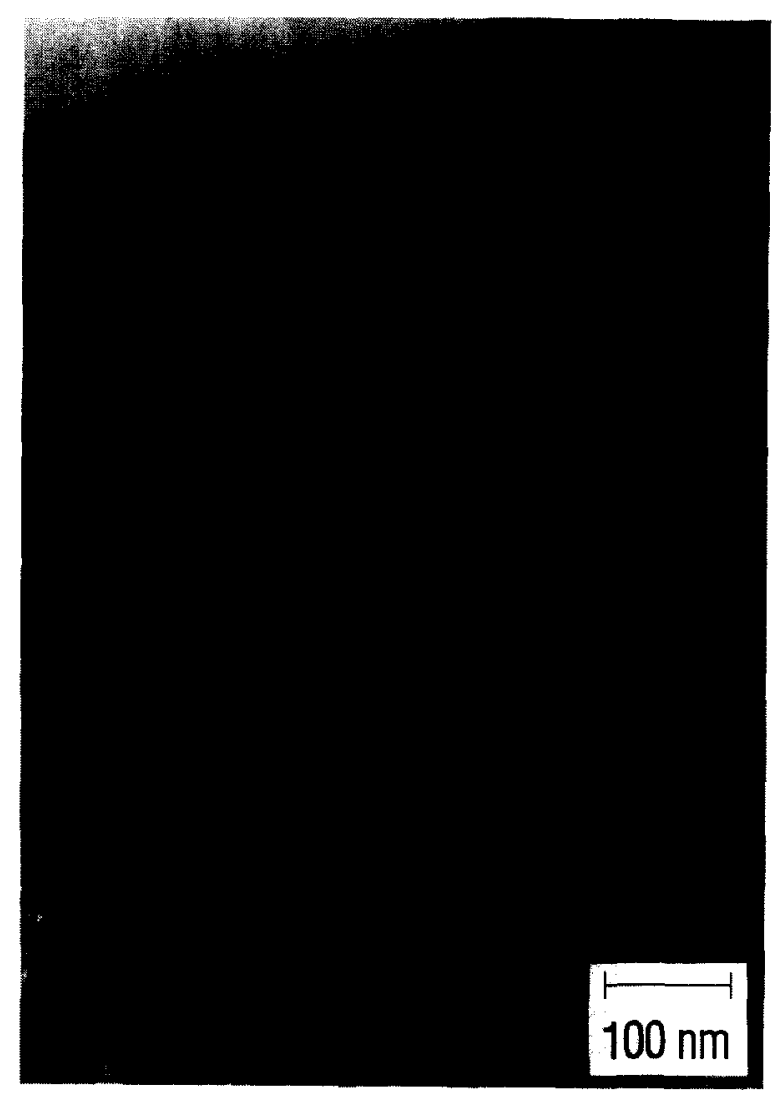

Fig. 3. TEM micrograph of copolymer 3.

Convincing evidence that nanofoams can be generated via this process is shown in Figs. 3 and 4. Here transmission electron micrographs (TEM) of copolymers 3 and 5, with different labile blocks, are shown. In these figures, the porous structure of the foam is clearly evident by the white areas in the micrographs which are the foamed voids from the degraded labile phase. The average size of the pores is $\sim 60 \AA$ for copolymer 3 . The periodic nature of the pores is clearly evident. On the other hand, the foams derived from the a-methylstyrene copolymer (copolymer 5) had pore sizes ranging from 200 to $\sim 1800 \AA$ A, which are considerably larger than the size of the original microdomains of the starting copolymer. Furthermore, these pores appear to be more interconnected than those obtained from poly(propylene oxide)-based copolymers and not spherical in shape. The size and shape of these pores are believed to be a result of concurrent plasticization (from these degr,adation products) and 'blowing' resulting in a large interconnected pore. 
Published in: Reactive \& Functional Polymers (1996), vol. 30, iss. 1-3, pp. 43-53

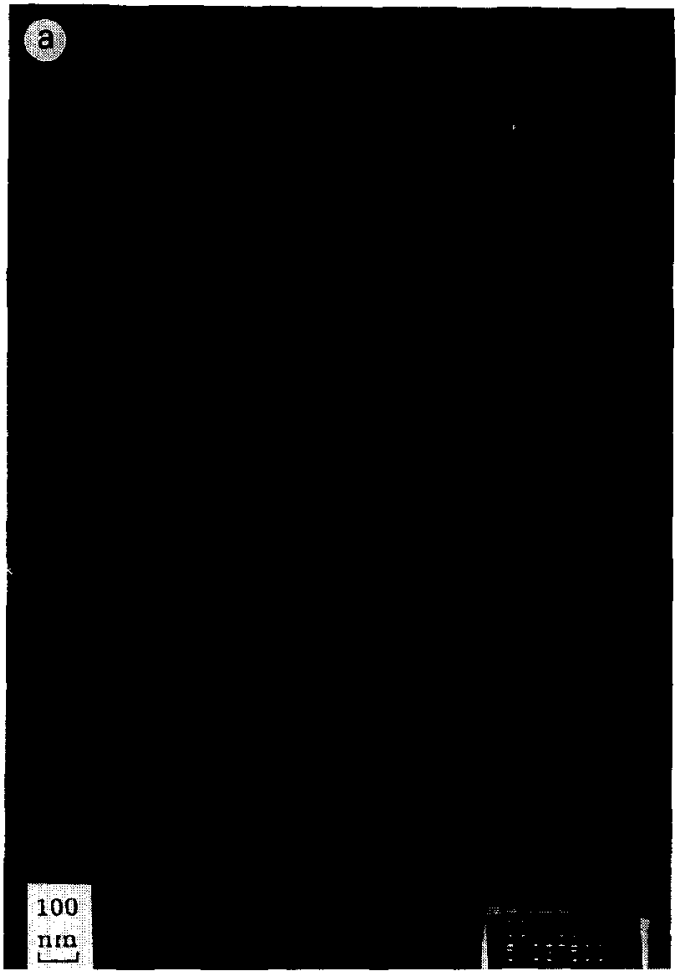

(b) 


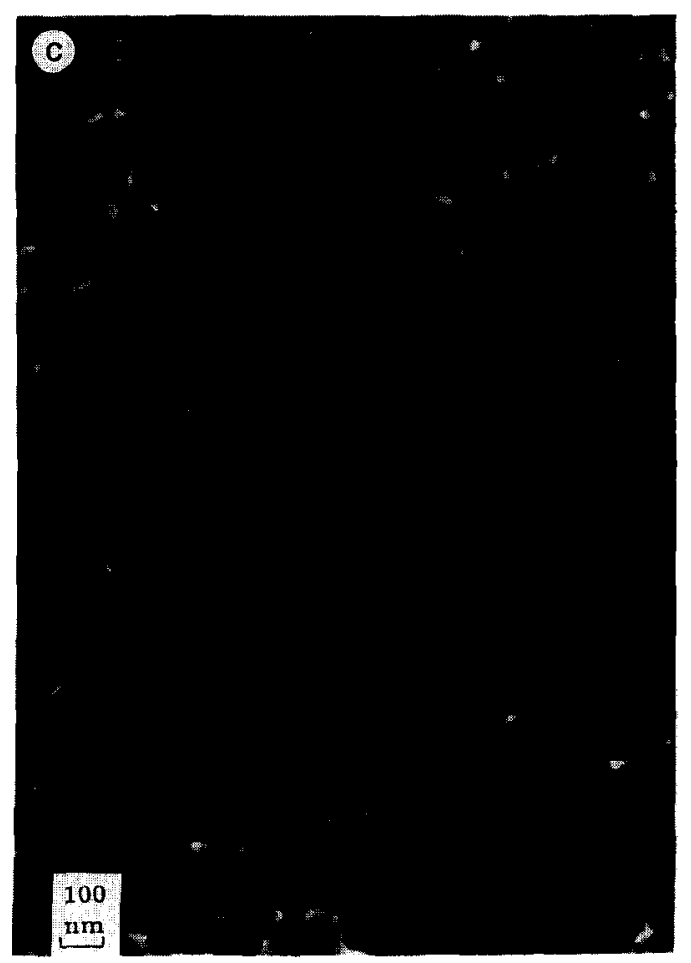

Fig. 4. TEM micrograph of copolymer 4.

To obtain a rough estimate of the dielectric properties of the thin films, we measure the refractive indices of thin film foamed samples. We have accurately measured the anisotropy (the difference between the in-plane and out-of-plane refractive indices) and have further observed that the measured dielectric constant is approximately the square of the refractive index [the actual relationship is roughly $\left.\varepsilon=(\text { refractiveindex })^{2}+0.2\right]$. Interestingly, the measured anisotropy of the foamed polyimides is lower than that observed for non-foamed polyimides. As expected, we also observed a drop in refractive index of samples upon foaming. The matrix polyimide ho-mopolymer PMDA/3FDA has a measured dielectric constant of 2.9. A foamed sample of PMDA/3FDA derived from a 24\% propylene oxide-based copolymer shows a substantial drop in dielectric constant to 2.3.

\section{References}

[1] R.R. Tummala and E.J. Rymaszewski. Microelectronics Packaging Handbook. Van Nostrand Reinhold. New York, 1989. Chap. I. [2] S. Numata, K. Fujisaki. D. Makino and N. Kinjo. Proceedings of the 2nd Technical Conference on Polyimides, Society of Plastic Engineers, Inc., October 1985, Ellenville, New York, p. 164.

3] J. Pfeiffer and 0. Rhode. Proceedings of the 2nd Technical Conference on Polyimides, Society of Plastic Engineers, Inc., October 1985, Ellenville. New York, p. 336.

[4] P.E. Cassidy, Thermally Stable Polymers: Synthesis and Properties. Marcel Dekker, New York, 1980.

[5] K.L. Mitral (Ed.). Polyimides. Plenum Press. New York, 1984.

[6] J.H. Lupinski and R.S. Moore (Eds.), Polymeric Materials for Electronic Packaging and Interconnection. ACS Symposium Series 407. 1989.

[71 N. Takahashi. D.Y. Yoon and W. Parrish. Macromolecules.17(1984)2583.

[8] D.Y. Yoon, W. Parish. L.W. Depro and M. Ree, Mater. Res. Sot. Symp. Proc., 227 (1991) 387.

[9] T.P. Russell, J. Polym. Sci. Polym. Phys. Ed.. 22 (1986) 1105.

[10] T.P. Russell, H. Gugger and J.D. Swalen. J. Polym. Sci. Polym. Phys. Ed., 21 (1983) 1735.

[11] (a) S. Herminghaus, D. Boess, D.Y. Yoon and B.A. Smith. Appl. Phys. Lett., 59 (1991) 1043. (h) D. Boese, H. Lee. D.Y. Yoon. J.D. Swalen and J.F. Raholt, J. Polym. Sci. Part B: Polym. Phys. Ed.. 30(1992) 1321.

[12] M. Haidar. E. Chenevey, R.H. Vora, W. Cooper and M. Click a Jaffe. Mater. Res. Sot. Symp. Proc.. 227 (1991) 35.

[13] F.W. Harris, S.L.C. Hsu. C.J. Lee. B.S. Lee. F. Arnold and S.Z.D. Cheng. Mater. Res. Sot. Symp. Proc.. 227 (1991) 3.

[14] S. Sasaki. T. Matuora, S. Nishi and S. Ando, Mater. Res. Sot. Symp.. 227 (1991)49.

[15] A.K. St. Clair, T.L. St. Clair and W.P. Winfree. Proc. Am. Chem. Sot. Div. Polym. Mater.: Sci. Eng., 59 (1988) 28.

[16] M.E. Rogers. T.M. Moy. Y.S. Kim and J.E. McGrath. Mater. Plas. Sot. Symp., I3 (1992) 264.

[17] W. Volksen. D.Y. Yoon. J.L. Hedrick and D. Hofer, Mater. Plac. Sot. Symp., 227 (1992) 23.

[18] Y. Charlier, J.L. Hedrick. T.P. Russell. R. DiPietro and R. Jerome, Polymer (1994). accepted.

[19] J. Hedrick, Y. Charlier, T.P. Russell, S. Swanson and M. Sanchez, J. Polym. Sci. Polym. Chem. Ed.. ?? (1994) ?‘?.

[20] J.L Hedrick, R. DiPietro. C.J.G. Plummer. J. Hilhorn and R. Jerome. Polymer (1994). submitted.

[21] J.L. Hedrick. R. DiPietro. Y. Charlier and R. Jerome. High Performance Polymers (I994). accepted.

[22] J.L. Hedrick, R. DiPietro, C. Hawker and R. Jerome, Polymer (1995) accepted.

[23] C.J Hawker and J.L. Hedrick, Macromolecules. 28 (1995) 2993.

[24] J.L. Hedrick, J. Labadie. T.P. Russel. D. Hofer and V. Wakharkar, Polymer, 34 C1993) 4717. 
Published in: Reactive \& Functional Polymers (1996), vol. 30, iss. 1-3, pp. 43-53

Status: Postprint (Author's version)

[25] Y. Charlier, J.L. Hedrick. T.P. Russell and W. Volksen, Polymer, 34 (1994)4717.

[26] ME. Rogers, M.H. Brink, J.E. McCrath and A. Brennan, Polymer. 34(1993)849.

[27] M. Sanchez, J.L. Hedrick and T.P. Russell, J. Polym. Sci. Polym. Phys. Ed., 33 (1995) 23. 